\title{
Impact of additional surface observation network on short range weather forecast during summer monsoon 2008 over Indian subcontinent
}

\author{
Prashant Kumar ${ }^{*}$, Randhir Singh, P C Joshi and P K Pal \\ Meteorology and Oceanography Group, Space Applications Centre (ISRO), Ahmedabad 380 015, India. \\ *e-mail:kam3545@gmail.com prashant22@sac.isro.gov.in
}

The three dimensional variational data assimilation scheme (3D-Var) is employed in the recently developed Weather Research and Forecasting (WRF) model. Assimilation experiments have been conducted to assess the impact of Indian Space Research Organisation's (ISRO) Automatic Weather Stations (AWS) surface observations (temperature and moisture) on the short range forecast over the Indian region. In this study, two experiments, CNT (without AWS observations) and EXP (with AWS observations) were made for 24-h forecast starting daily at 0000 UTC during July 2008. The impact of assimilation of AWS surface observations were assessed in comparison to the CNT experiment. The spatial distribution of the improvement parameter for temperature, relative humidity and wind speed from one month assimilation experiments demonstrated that for 24-h forecast, AWS observations provide valuable information. Assimilation of AWS observed temperature and relative humidity improved the analysis as well as 24 -h forecast. The rainfall prediction has been improved due to the assimilation of AWS data, with the largest improvement seen over the Western Ghat and eastern India.

\section{Introduction}

The problem of determining a physically consistent and accurate snapshot of the atmosphere is the central aim of numerical weather prediction (NWP). In succeeding decades, with progress in both computing power and optimization strategies, more sophisticated constraints and more diverse observations have been included in NWP. Obtaining an accurate model at the initial state is recognized as one of the biggest challenges in model prediction of weather events. The rapid growing computer power has led to finer resolution NWP models, which are able to resolve mesoscale features and thus to give more precise forecasts. Automatic Weather Stations (AWS) for surface level meteorological observations are valuable data sources for mesoscale data assimilation and forecasting (Ruggiero et al 1996). Assimilating surface observations into NWP models significantly reduced modelling errors in the atmospheric boundary layer (Alapaty et al 2001). Although surface observations do not produce direct observations of the upper air, Yee and Jackson (1988) have outlined a scheme where differences between surface observations and the bottom layer model forecast can be used to adjust the other model layers. Since AWS data is influenced by topography, there exists large difference between observation (AWS) and model surface elevation and AWS elevation is corrected here before assimilation. Not much work has been done to assimilate these data into numerical models compared to other data (radiosonde, satellite or radar data). Guo et al (2002) developed an observation operator and its corresponding adjoint to assimilate AWS surface observations, based on the similarity theory and performed some sensitivity experiments with surface data with

Keywords. WRF model and 3D-Var; ISRO AWS; rainfall; threat score. 


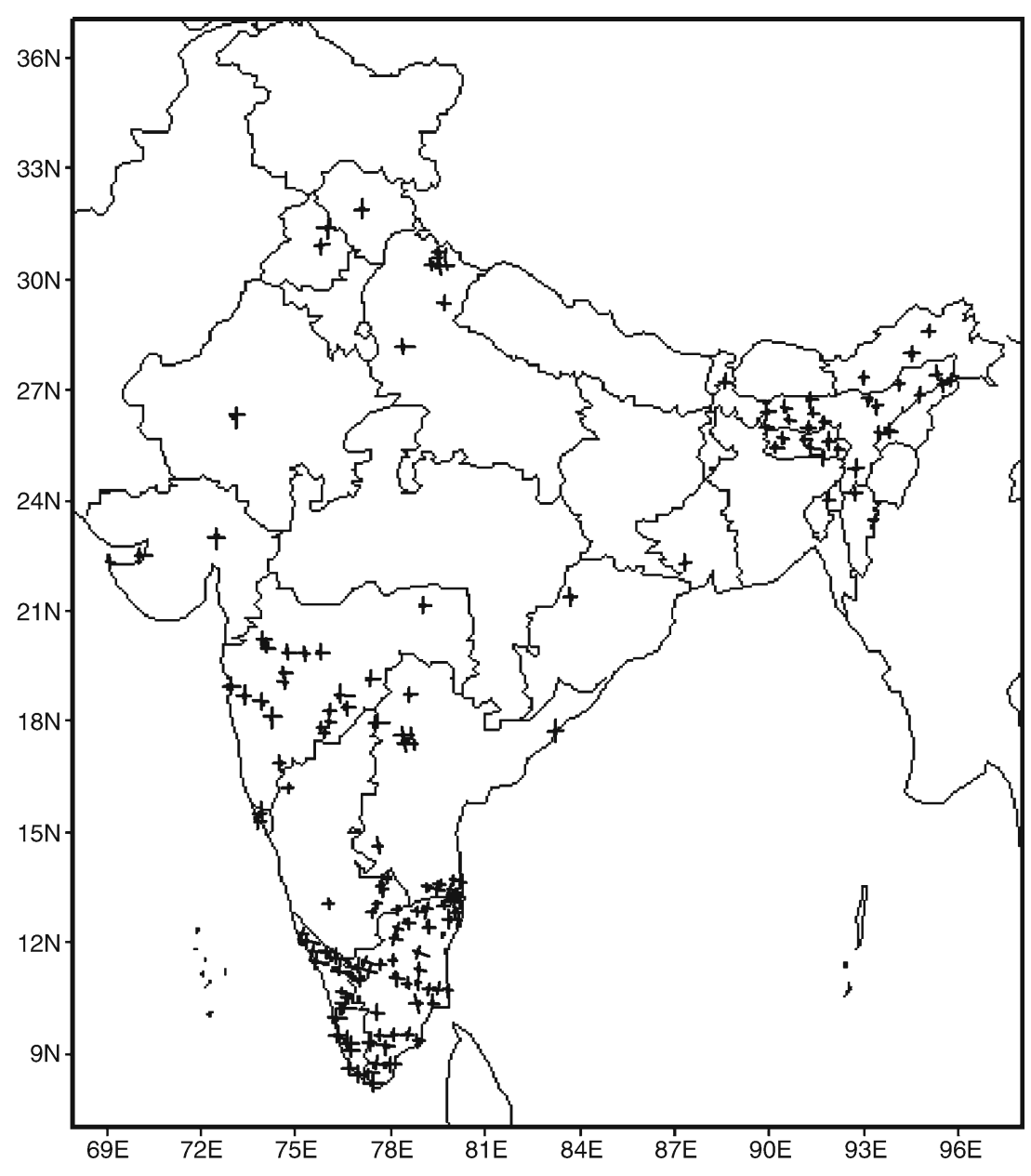

Figure 1. Distribution of ISRO's AWS during July 2008.

MM5 3D-Var system. They showed that 3D-Var assimilation of high-resolution Korea Meteorological Administration (KMA) AWS data could substantially improve the model skill in short-range prediction of heavy precipitation over the Korean peninsula.

Indian Space Research Organization (ISRO) has recently deployed a high-density network of AWS over whole of India to collect real-time observations of surface meteorological parameters including temperature, wind speed and direction, relative humidity, pressure, and rainfall at high temporal resolution. There are almost more than 950 ISRO's AWS stations in India, while many more are planned to be installed in future to enhance the observation system comprehensively. Detailed location of AWS can be seen on website: http://www.mosdac.gov.in. The primary purpose for the deployment of the AWS is to support high resolution operational forecasting. In the present study, we have used the Weather Research and Forecasting (WRF; Skamarock et al 2008) model, to investigate the potential impact of ISRO's AWS data on short-range forecasts. In this paper, section 2 describes the data used for the assimilation in this study. The description of WRF model, assimilation methodology, and the design of numerical experiments are discussed in section 3. The initialization and simulation results are shown in section 4. The results are summarized in section 5 .

\section{Data used for assimilation}

As initiated by ISRO's Prediction of Regional Weather with Observational Meso-Network and Atmospheric Modeling (PRWONAM) programme, the ISRO has installed AWS stations (figure 1) throughout India to increase the high resolution observational network. The low-cost AWS is compact, modular, rugged and capable of operating with minimum power from battery and solar panel for extended periods in the field conditions even in remote areas where power supply and communication facilities are not available. AWS can continuously record weather data like temperature, atmospheric pressure, wind speed and direction, 

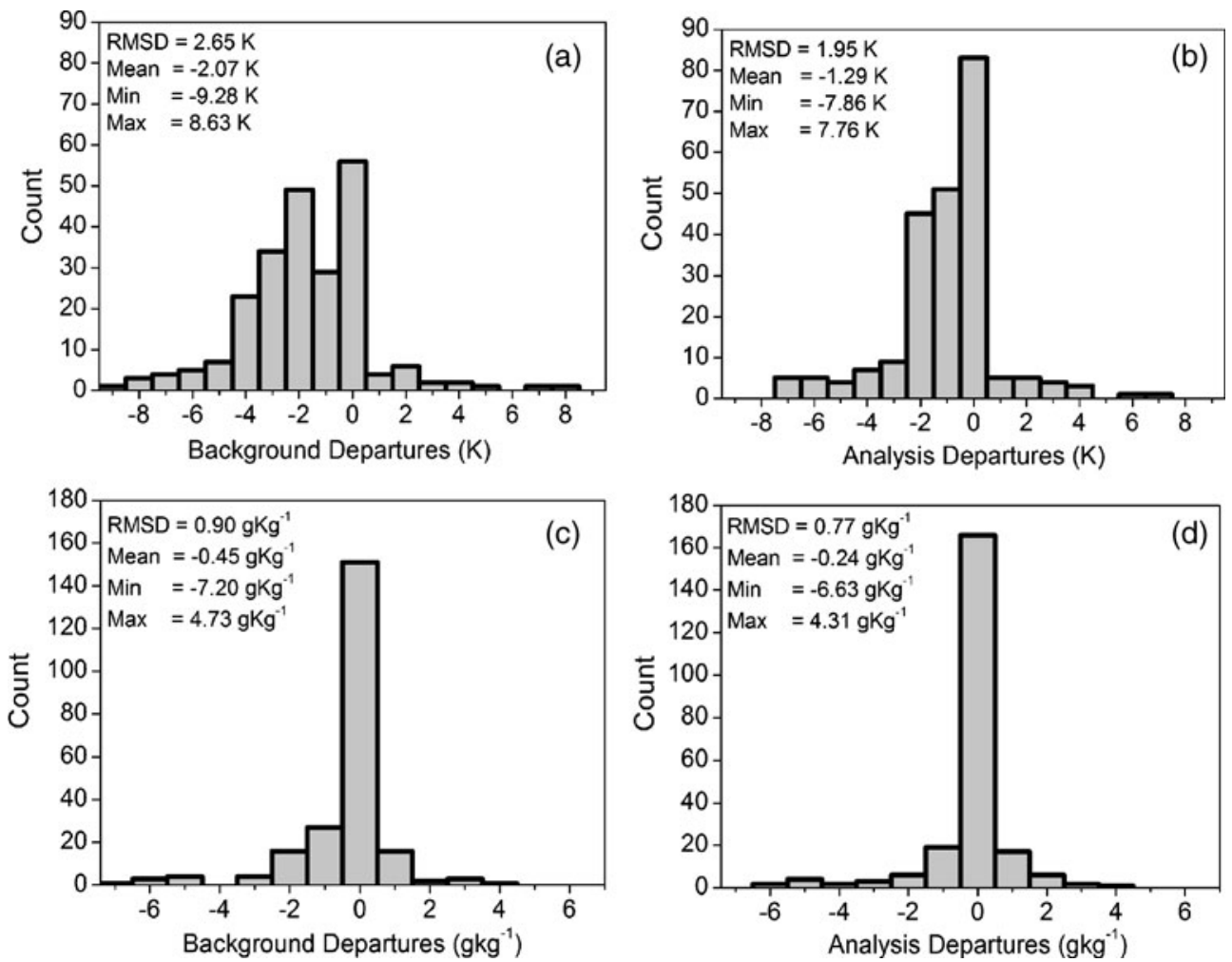

Figure 2. Histogram of (a) background departure $(\mathrm{O}-\mathrm{B})$ for temperature, $(\mathbf{b})$ analysis departure $(\mathrm{O}-\mathrm{A})$ for temperature, (c) background departure $(\mathrm{O}-\mathrm{B})$ for specific humidity, and $(\mathbf{d})$ analysis departure $(\mathrm{O}-\mathrm{A})$ for specific humidity at $0000 \mathrm{UTC}$ 1 July 2008.

rainfall, relative humidity, solar radiation, etc. The data from a large number of AWS located across the country collected through the Data Relay Transponder onboard the ISRO's INSAT (Kalpana-1 and INSAT-3A) satellites. The data logger measures each input once per second except for barometric pressure, which is measured once per minute. The data logger produces 1- and 30-min vector-averaged wind speed and direction, air temperature and relative humidity. The observed data are archived at Meteorological and Oceanographic Satellite Data Archival Centre (MOSDAC) of Space Applications Centre, ISRO. In addition to AWS, radiosonde, ships, NASA Quick Scatterometer (QuikSCAT) wind, and Special Sensor Microwave/Imager (SSMI) wind and Total Water Precipitation (TWP) observations were used for the assimilation.

\section{WRF model and assimilation methodology}

\subsection{WRF model}

The forecast model used in this study is the Weather Research and Forecasting (WRF; Skamarock et al 2008) model version 3.1. WRF is a limited area, non-hydrostatic, primitive equation model with multiple options for various physical parameterization schemes. This version employs Arakawa C-grid staggering for the horizontal grid and a fully compressible system of equations. The terrain following hydrostatic pressure coordinate with vertical grid stretching was followed in vertical. The time-split integration uses 3rd order Runge-Kutta scheme with a smaller time step for acoustic and gravity wave modes. The WRF physical options used in this study consists of the WRF Single Moment 3-class simple ice scheme for microphysics (WSM3), which is similar to that used by Lin et al (1983); the new Kain-Fritsch (Kain 2004) cumulus convection parameterization scheme; and the Yonsei University (YSU) planetary boundary layer scheme (Hong and Pan 1996; Hong and Dudhia 2003). The Rapid Radiative Transfer Model (RRTM; Mlawer et al 1997) and Dudhia scheme (Dudhia 1989) were used for longwave and shortwave radiations, respectively. All experiments were conducted with nested domain; outer domain (long.: $32.7^{\circ}-121.2^{\circ} \mathrm{E}$, lat.: $26.1^{\circ}-$ $52.3^{\circ} \mathrm{N}$ ) consisting of $330 \times 330$ grid points with $30 \mathrm{~km}$ horizontal grid resolution and inner domain (long.: $65.6^{\circ}-100.5^{\circ} \mathrm{E}$, lat.: $5.8^{\circ}-37.8^{\circ} \mathrm{N}$ ) contains $391 \times 391$ grid points with $10 \mathrm{~km}$ horizontal grid resolution. The model had 36 vertical levels with the top of the model atmosphere located at $10 \mathrm{hPa}$. 


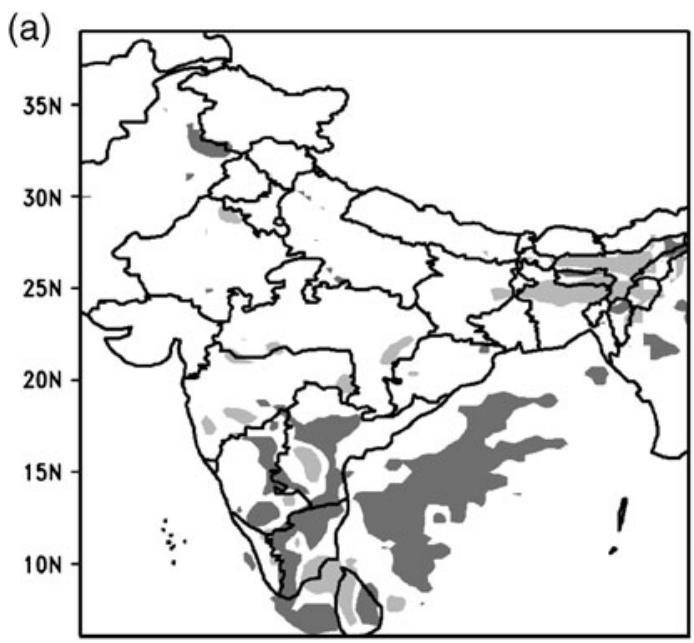

(b)

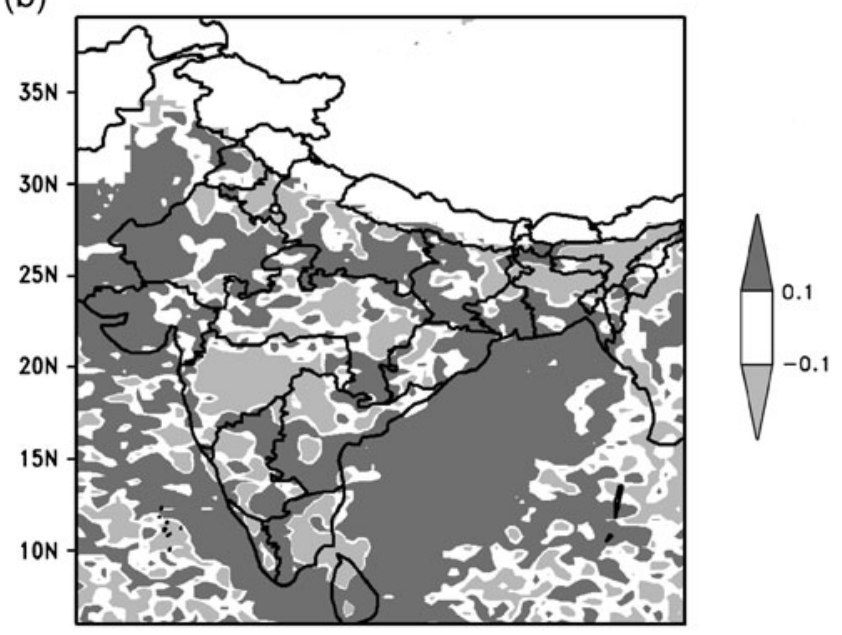

(c)

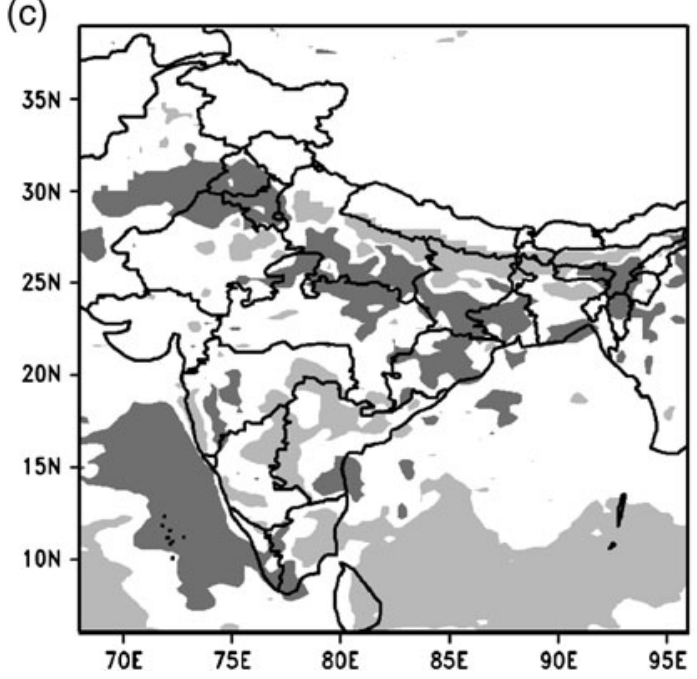

Figure 3. Spatial distribution of improvement parameter in analyzed $850 \mathrm{hPa}$ (a) temperature, (b) relative humidity, and (c) wind speed at 0000 UTC during July 2008.

\subsection{Assimilation methodology}

The WRF three-dimensional variational data assimilation system, WRF 3D-Var (Skamarock et al 2008) was used in the present study. The WRF 3D-Var were developed from the MM5 3D-Var (Barker et al 2004), but the basic software interface and coordinate framework were fully updated for the WRF model. The configuration of the WRF 3D-Var system is based on an incremental formulation producing a multivariate incremental analysis in the WRF model space. The incremental cost function minimization is performed in a preconditioned control variable space. The preconditioned control variables used in this study were stream-function, velocity potential, unbalanced pressure and specific humidity. Statistics of differences between $24 \mathrm{~h}$ and $12 \mathrm{~h}$ forecasts are used to estimate background error covariances matrix via the National Meteorological Center (NMC) method (Parrish and Derber 1992; $\mathrm{Wu}$ et al 2002). Representation of the horizontal component of background error is via horizontally isotropic and homogeneous recursive filters. The vertical component is applied through projection onto climatologically averaged eigenvectors of vertical error estimated via the NMC method. A detailed description of the 3D-Var system can be found in Barker et al (2004).

\subsection{Design of numerical experiments}

Two experiments were performed daily at 0000 UTC during July 2008 using WRF 3DVar (with and without assimilation). Instead of directly using the National Centers for Environmental Prediction (NCEP) FNL analysis for the first guess (FG), 6-h WRF forecasts valid at 1800 UTC initialized using the NCEP FNL analysis at 1200 UTC were used as the FG for all 3D-Var experiments. From 1800 UTC to 0000 UTC, 3-hourly data assimilation cycling was performed. Prior to data assimilation, all data underwent quality checking process in order to reduce the possibilities of assimilating bad observations. The NCEP FNL analysis with $1^{\circ} \times 1^{\circ}$ resolution was utilized for the model boundary conditions for all the experiments. A $24-h$ forecast was made daily from 0000 UTC during July 2008 with CNT (without AWS data) and EXP (with AWS data) initial conditions.

\section{Assimilation results}

\subsection{Overview of the fit to observations}

In a successful assimilation, the analysis departures (observed minus analysis; also known as $\mathrm{O}-\mathrm{A}$ ) are smaller than the first guess departures (observed minus background; also known as $\mathrm{O}-\mathrm{B}$ ). Figure 2 


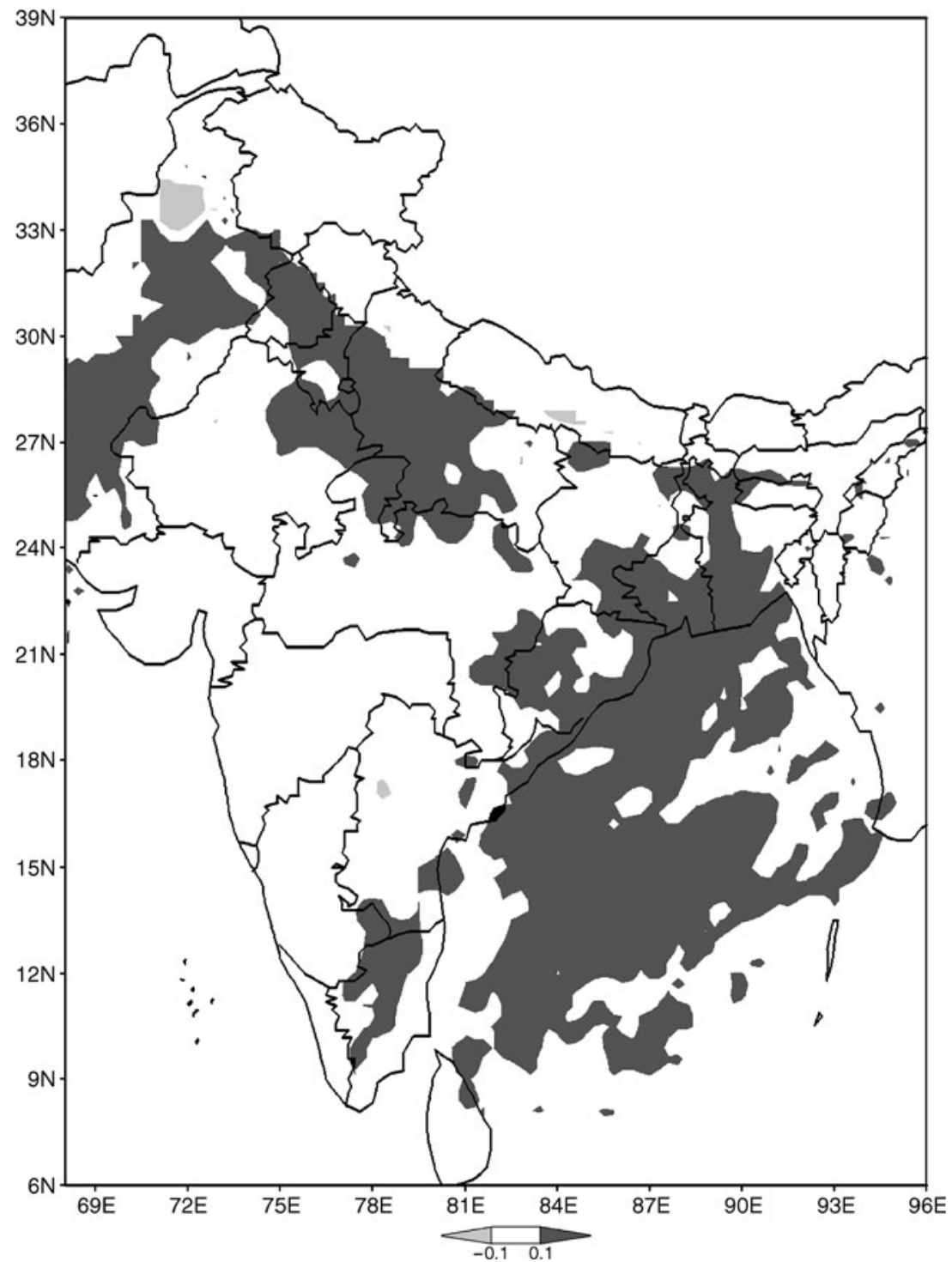

Figure 4. Spatial distribution of improvement parameter for $850 \mathrm{hPa}$ temperature 24-h forecast.

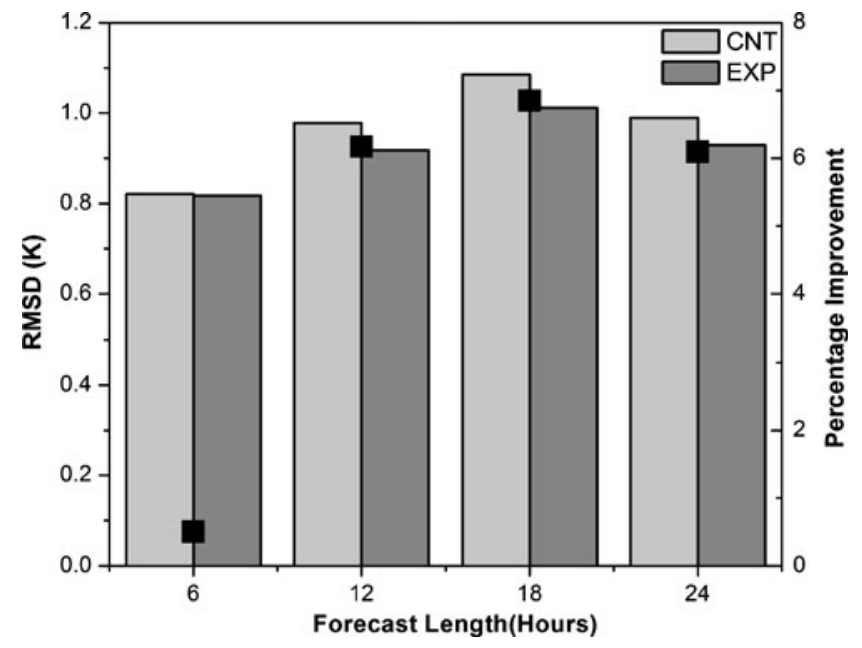

Figure 5. Domain averaged RMSD for $850 \mathrm{hPa}$ temperature for different forecast time and square shows the percentage improvement. shows the histogram of first guess and analysis departures for AWS temperature and specific humidity at 0000 UTC, 1 July 2008. The first guess and analysis departures have root mean square difference (RMSD) of 2.65 and $1.95 \mathrm{~K}$, respectively. The mean differences are reduced from $-2.07 \mathrm{~K}(\mathrm{O}-\mathrm{B})$ to $-1.29 \mathrm{~K}(\mathrm{O}-\mathrm{A})$. In case of specific humidity, the mean differences are reduced from $-0.45 \mathrm{gkg}^{-1}(\mathrm{O}-\mathrm{B})$ to $-0.24 \mathrm{gkg}^{-1}(\mathrm{O}-\mathrm{A})$, while RMSD is decreased from $0.90-0.77 \mathrm{gkg}^{-1}$. This shows that analysis better matches with the observations than background, which confirms the successful assimilation of AWS observations with WRF 3D-Var.

\subsection{Impact of AWS data on the analysis}

To estimate the improvement due to assimilation of AWS data, we have computed the spatial 


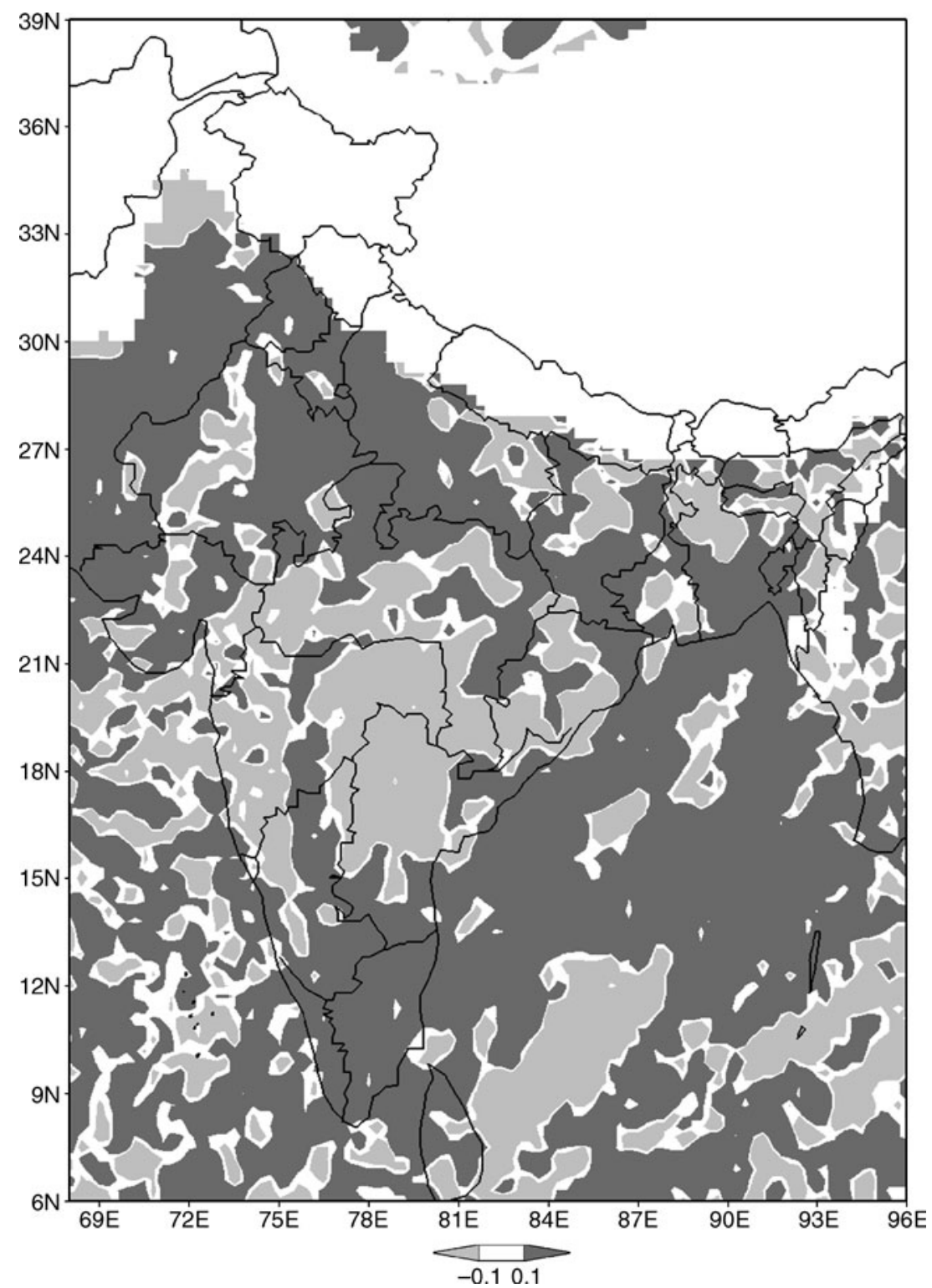

Figure 6. Spatial distribution of improvement parameter for $850 \mathrm{hPa}$ relative humidity 24-h forecast.

distribution of improvement parameter $(\eta)$ in temperature $(\mathrm{K})$, relative humidity (\%) and wind speed $(\mathrm{m} / \mathrm{s})$ between EXP and CNT produced analyses. The improvement parameter used to quantify the improvement is given below.

$$
\begin{aligned}
\eta= & {\left[\frac{1}{N} \sum_{i=1}^{N}\left(O_{i}^{a}-C_{i}^{a}\right)^{2}\right]^{1 / 2} } \\
& -\left[\frac{1}{N} \sum_{i=1}^{N}\left(O_{i}^{a}-E_{i}^{a}\right)^{2}\right]^{1 / 2},
\end{aligned}
$$

where $C$ is the analysis produced without AWS data and $E$ is the analysis produced with the assimilation of AWS data and $O$ is the NCEP analysis, where superscript $a$ represents the analysis and $N$ is the total number (30 in this case) of analyses.

Figure $3(\mathrm{a}-\mathrm{c})$ shows the improvement parameter in initial temperature, relative humidity and wind speed at $850 \mathrm{hPa}$. The positive (negative) values of $\eta$ show the improvement (degradation) in the analyzed fields due to the assimilation of AWS data. The assimilation of AWS data shows improved temperature analysis (figure 3a) over the Bay of Bengal and southern part of India, while over some parts of eastern India, the assimilation of AWS data degraded the temperature analysis. Similarly, the improved analysis of moisture (figure $3 \mathrm{~b}$ ) is obtained over western region of India and Bay of Bengal after assimilation of AWS data. It is interested to see that analysis is improved over 


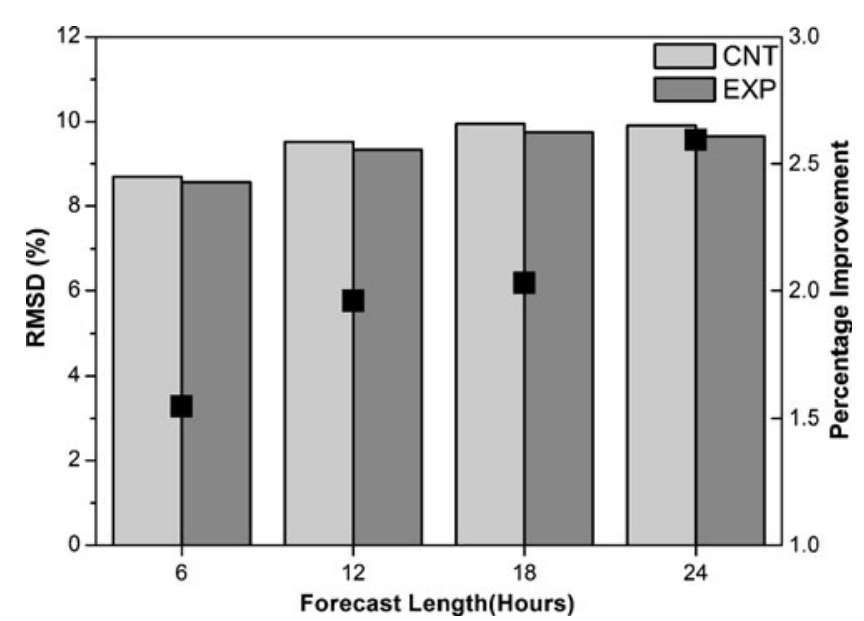

Figure 7. Domain averaged RMSD for $850 \mathrm{hPa} \mathrm{RH}$ for different forecast time and square shows the percentage improvement.

the Bay of Bengal as well as over Gangetic region, where there was no AWS data available. The information content of AWS observations is advected from data-rich to data-poor areas with the help of data assimilation in cyclic mode. In the cyclic data assimilation, model integrates forward in time and the information content propagates with the model flow. Advection of observations from data rich regions to data sparse regions via assimilation/model dynamics has also been emphasized by earlier studies (Ehrendorfer 1992; Wang et al 2008; Rakesh et al 2009a, 2009b).

The useful AWS informations were advected from land region (e.g., Tamil Nadu and Kerala coast) to the Bay of Bengal by strong westerly flow over the southern part of India. The improved analysis and forecast over Gangetic region might have been due to the advection of information (from Bay of Bengal) by Bay of Bengal branch of the monsoon that is diverted westward up the Gangetic region of India. The negative impacts of AWS data on moisture fields are seen over Maharashtra and some isolated pockets over Tamil Nadu. One of the reasons of slight negative to neutral impact of AWS data over these data rich regions may be the fast advection of the AWS informations from these regions. Another reason may be the specifications of the background and observations error statistics in the assimilation system. In the present study, though the AWS winds were not assimilated, still some improvements are seen in the analyzed winds over Central India and Western Ghats (figure 3c), which may be due to the multivariate nature of WRF 3D-Var. Results were also analyzed for the $300 \mathrm{hPa}$, which showed that the impact of AWS data was positive but less in magnitude as compared to the $850 \mathrm{hPa}$.

\subsection{Impact of AWS data on the forecast}

Here we have considered RMSD in the forecast fields as a standard measurement for evaluating model performance. The NCEP analysis and AWS data have been used for computing the RMSD in the CNT and EXP predicted temperature, moisture and wind speed. We have analyzed the spatial distribution of RMSD in the $24 \mathrm{~h}$ predicted temperature, moisture and wind speed. As in the analysis, we have also computed the improvement parameter in the forecasts. The improvement parameter $(\delta)$ used to quantify the improvement in the forecast is given below.

$$
\begin{aligned}
\delta= & {\left[\frac{1}{N} \sum_{i=1}^{N}\left(O_{i}^{a}-C_{i}^{f}\right)^{2}\right]^{1 / 2} } \\
& -\left[\frac{1}{N} \sum_{i=1}^{N}\left(O_{i}^{a}-E_{i}^{f}\right)^{2}\right]^{1 / 2},
\end{aligned}
$$

where $C$ is the forecast produced without AWS data and $E$ is the forecast produced with the assimilation of AWS data and $O$ is the observation (AWS for surface and NCEP analysis for $850 \mathrm{hPa}$ ), where superscript $f$ represents the forecast and $N$ is the total number of forecasts, which are 30 in this case. A positive (negative) value of $\delta$ indicates improvement (degradation) in the forecast due to AWS data assimilation as compared to CNT.

\subsubsection{Temperature}

The analysis of $\delta$ indicates (not shown) that AWS data has positive impact on 2-m temperature forecasts over northern and southern parts of India and negative impact over eastern India. The 24-h predicted $850 \mathrm{hPa}$ temperature from both the experiments has been compared with the NCEP analysis. The assimilation of AWS data showed improved temperature prediction (figure 4; positive area is more than negative area) as compared to the control. The largest improvement is seen in northern India and Bay of Bengal. Figure 5 shows temporal (6 hourly) evolution of the domain averaged RMSD for CNT and EXP predicted $850 \mathrm{hPa}$ temperatures. With respect to NCEP analysis, the RMSD in predicted temperature is lower (figure 5) in case of AWS data assimilation experiment than control.

\subsubsection{Relative humidity}

The $24 \mathrm{~h}$ predicted relative humidity $(\mathrm{RH})$ at $2 \mathrm{~m}$ height from both the experiments was compared with AWS observed RH. The geographical distribution of $\delta$ (not shown) for different parts of 


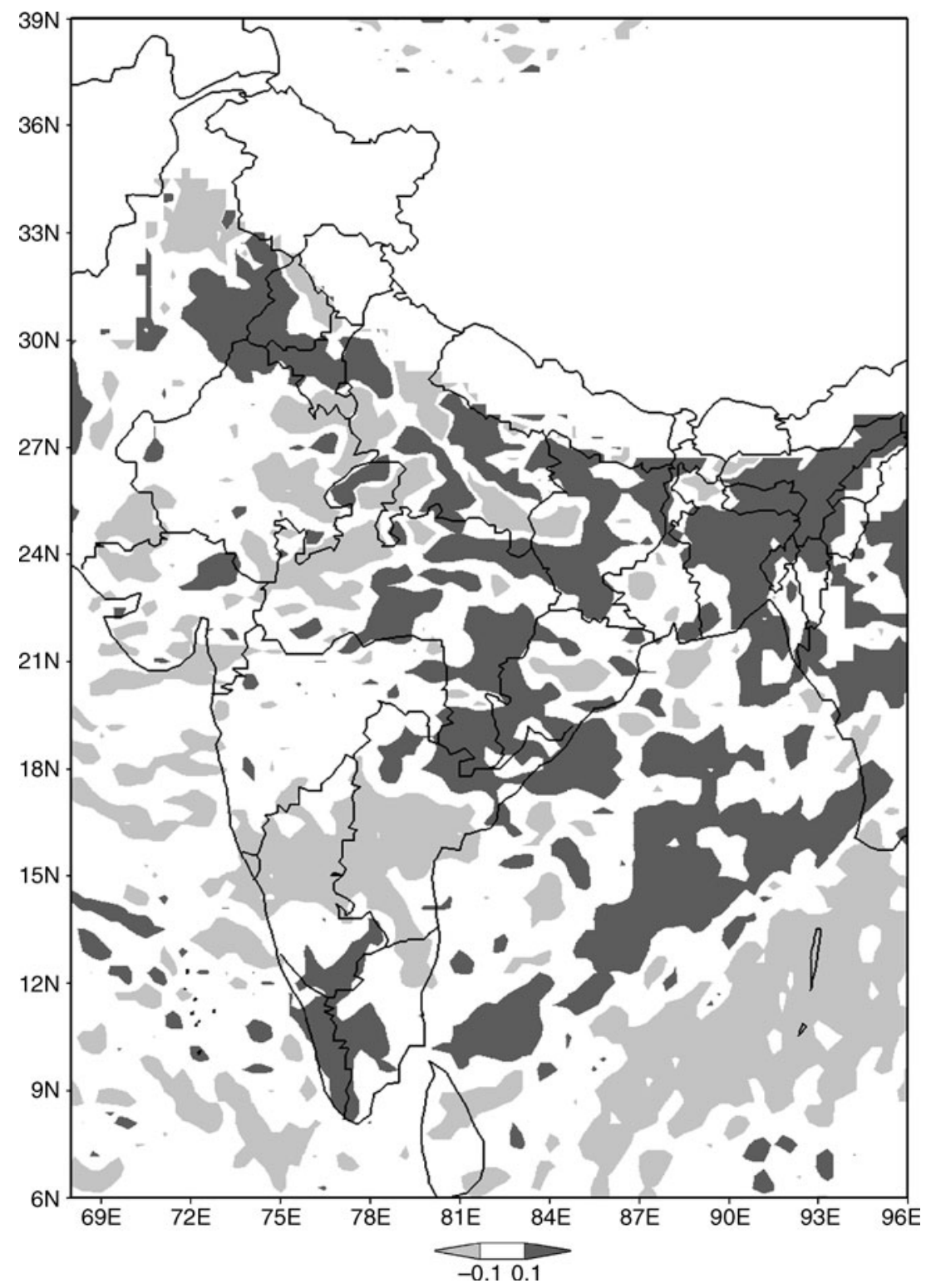

Figure 8. Spatial distribution of improvement parameter for $850 \mathrm{hPa}$ wind speed 24-h forecast.

the domain specify that AWS data has positive impact on predicted $2-\mathrm{m} \mathrm{RH}$ over northern and southern parts of the domain and small pockets of negative impact are seen over eastern part of the domain. We have also compared the $24 \mathrm{~h}$ predicted $850 \mathrm{hPa} \mathrm{RH}$ from CNT and EXP experiment with the NCEP analysis. Compared to the control run, the assimilation of AWS data positively (figure 6) impacted the $24 \mathrm{~h}$ prediction of $850 \mathrm{hPa}$ relative humidity. The largest positive impact is seen over northern part of India and Bay of Bengal. Figure 7 shows the temporal (6-hourly) evolution of the domain averaged RMSD for CNT and EXP predicted $850 \mathrm{hPa} \mathrm{RH}$. Compared to NCEP analysis, the RMSD in the predicted $\mathrm{RH}$ is lower in EXP than in CNT.

\subsubsection{Wind speed}

The $24 \mathrm{~h}$ predicted $850 \mathrm{hPa}$ wind speed (figure 8 ) from both the experiments was compared with the NCEP analysis. Spatial distribution of improvement parameter $(\delta)$ shows that the assimilation of AWS relative humidity and temperature also influenced the wind speeds positively, particularly over Western Ghats and eastern India. Some isolated pockets of negative impact are seen over south-eastern part of the domain.

\subsubsection{Rainfall}

Tropical Rainfall Measuring Mission (TRMM) 3B42 V6 product (Haddad et al 1997; Adler et al 
(a)

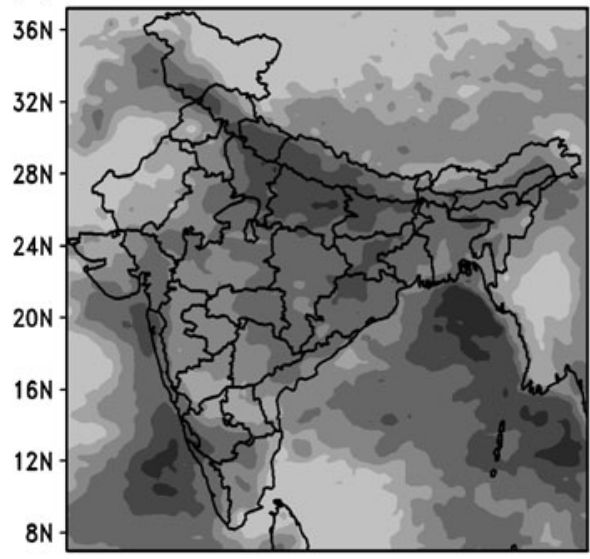

(c)

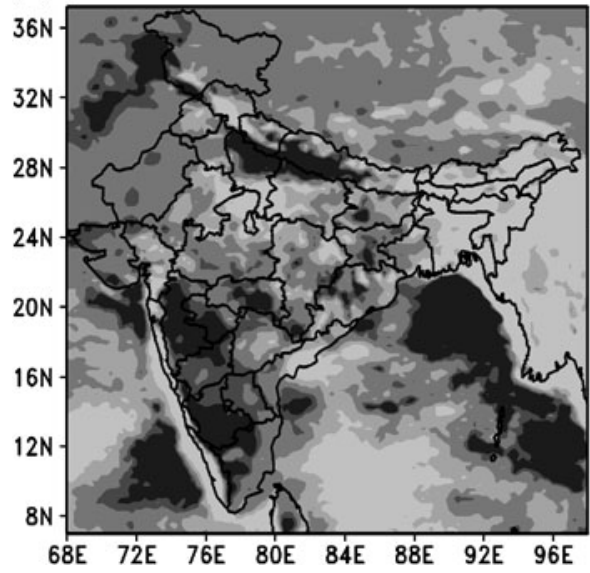

(b)

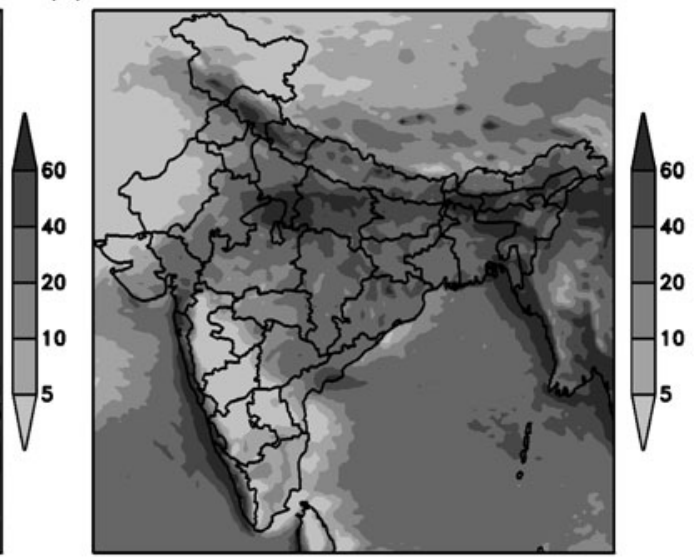

(d)

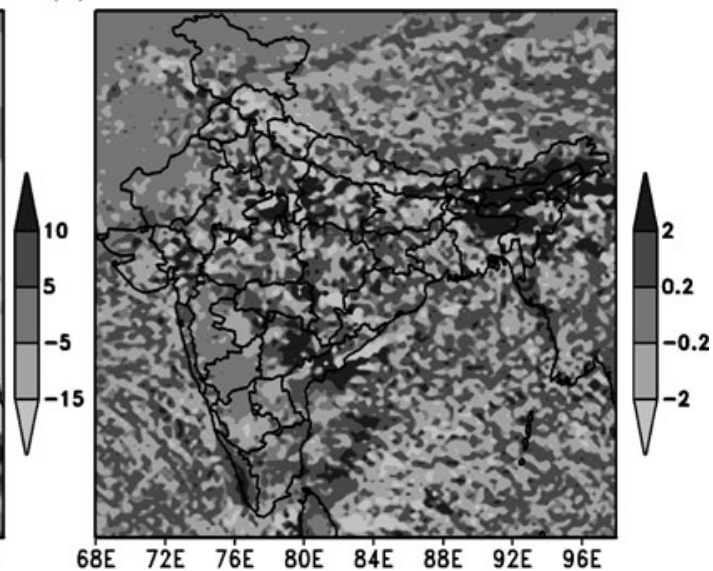

Figure 9. Accumulated rainfall for the month of July 2008 from (a) TRMM (cm), (b) CNT (cm), (c) TRMM-CNT (cm), and $(\mathbf{d})$ improvement parameter $(\mathrm{cm})$.

2000) was used for the verification of the model predicted rainfall over land as well as Oceanic region. The TRMM rainfall used for validation is at 3 -h temporal resolution and $0.25^{\circ} \times 0.25^{\circ}$ spatial resolution. The model-predicted rainfall for the inner domain was resampled to $25 \mathrm{~km}$ (using bilinear interpolation) in order to compare it with the TRMM rainfall. TRMM 3B42 algorithm's 3-h rain rate is converted to accumulated rainfall assuming constant rain rate over $3 \mathrm{~h}$. The monthly (July 2008) rainfall from TRMM (figure 9a) showed that the maximum monsoon rainfall was observed over the west coast of peninsular India, head Bay of Bengal and Gangetic Plain. Less precipitation was observed over central India, the eastern coast of southern peninsular India, and northwestern part of India. The accumulated rainfall from model (CNT) 24-h forecast is given in figure 9(b). The difference plot (figure 9c) of accumulated rainfall from TRMM and 24-h forecast (CNT) showed that $\mathrm{CNT}$ underpredicted the rainfall in southern region of Bangladesh, western and southern parts of India and overestimated in Western Ghats and eastern India. For the quantitative assessment of improvement (degradation) due to the assimilation of AWS data as compared to CNT, we have computed the spatial distribution of improvement parameter. It is clear from the figure $9(\mathrm{~d})$ that the rainfall prediction was improved (relative to the control simulation) by the incorporation of AWS data. Assimilation of AWS data improved the 24-h rainfall prediction over the west coast of India and eastern India. This impact is mainly due to the improvement in the lower level moisture fields. Over southern India and northeast India, compared to the control simulation, the rainfall is improved with the assimilation of AWS data. This is because the relative humidity and wind speed (figure 8) are better predicted in case of AWS data assimilation run. Though, some degradation is seen in the temperature prediction at surface due to the assimilation of the AWS data. In addition to TRMM, the model predicted rainfall is compared with IMD observed rainfall over the land area. 

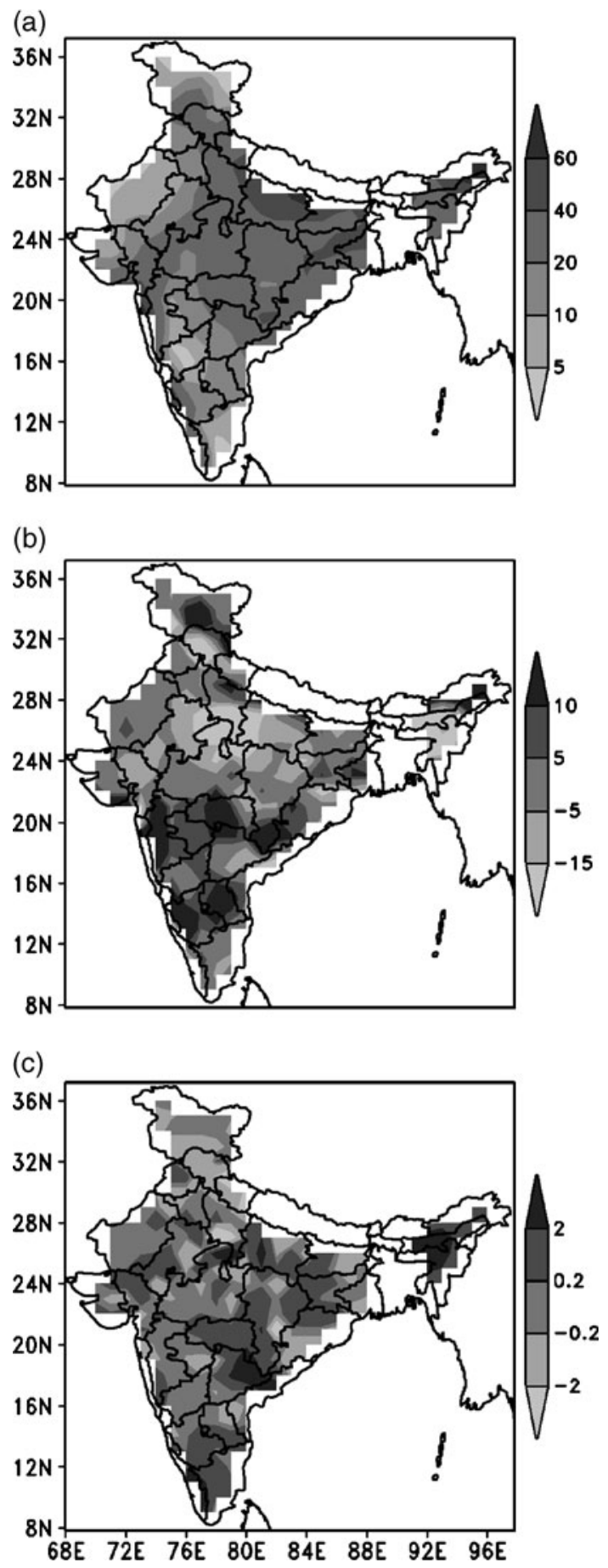

Figure 10. Accumulated rainfall for the month of July 2008 from (a) IMD (cm), (b) IMD-CNT (cm), and (c) improvement parameter $(\mathrm{cm})$.

The daily precipitation produced by the model (regridded at $1^{\circ} \times 1^{\circ}$ resolution) is compared with the daily gridded rainfall data of India Meteorological Department (IMD) at $1^{\circ} \times 1^{\circ}$ resolution (Rajeevan et al 2006) for the land areas. The monthly (July 2008) rainfall from IMD, the difference plot of accumulated rainfall from IMD and 24-h forecast (CNT) and the quantitative assessment of improve- (a)

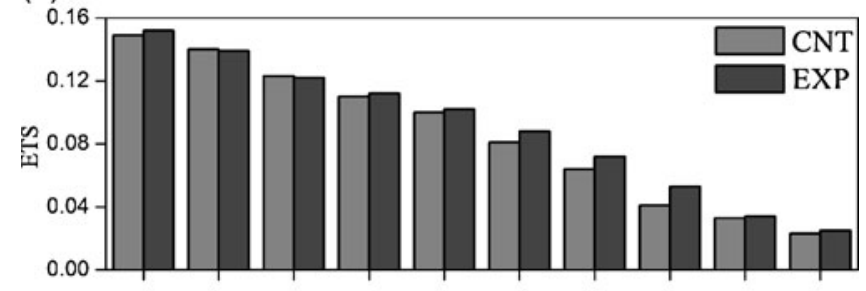

(b)

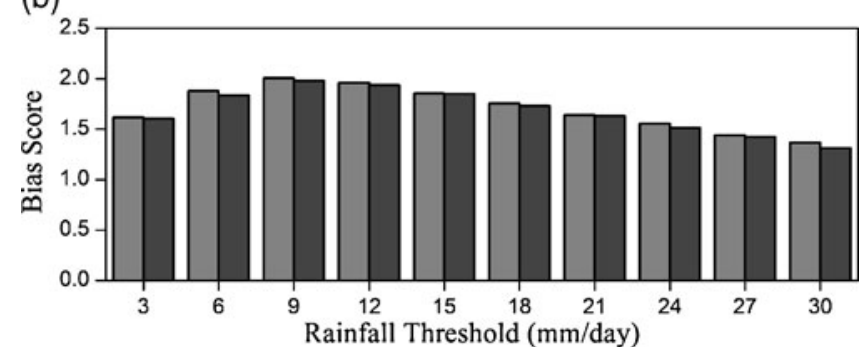

Figure 11. (a) Equitable threat score (ETS) and (b) bias in rainfall prediction with corresponding TRMM observations for different rainfall thresholds.

ment (degradation) due to the assimilation of AWS data as compared to CNT are given in figure 10 . The large scale difference pattern between IMD and model (CNT) predicted rainfall is similar to that of difference between TRMM and CNT, which shows that TRMM and IMD rainfall are closely matching with each other. Most of the regions, the rainfall prediction was improved (figure 10c; relative to the control simulation) by the incorporation of AWS data in the 24-h rainfall prediction over the west coast of India, southern and eastern India.

Another way of verifying a precipitation forecast is through the use of the equitable threat score (ETS) and bias statistics, both of which are based on a contingency table approach (Colle et al 1999). To examine the performance of CNT and EXP in reproducing the frequency of occurrence of rainfall events at or above a precipitation threshold, we have computed statistical skill scores (bias scores [BSs] and ETSs) for 24-h accumulated rainfall predictions. Similar to the previous results, these statistics are obtained by comparing 30 samples of daily accumulated rainfall predictions from both experiments with corresponding observed (from TRMM and IMD) rainfall for the period 2-31 July 2008 at various rainfall thresholds. Figure 11 shows the ETS and BS computed using TRMM data as the observed rainfall for different thresholds for the control and assimilation runs. It is seen from figure 11(a) that 24-h forecast from the WRF showed poor skill in reproducing the frequency of occurrence of accumulated rainfall at higher thresholds. Model skill deteriorated rapidly with rainfall threshold. For the 24-h accumulated rainfall, the marginal improvement (figure 11a) 
(a)

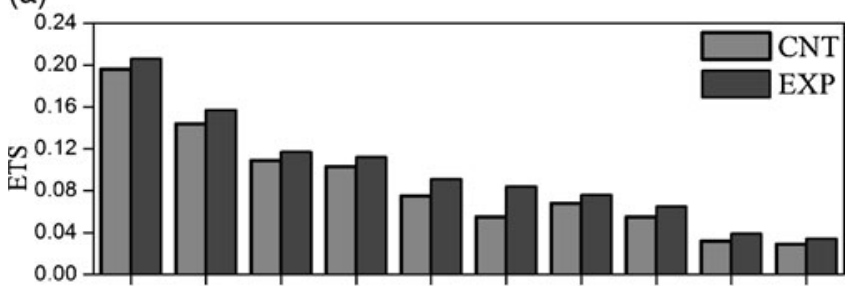

(b)

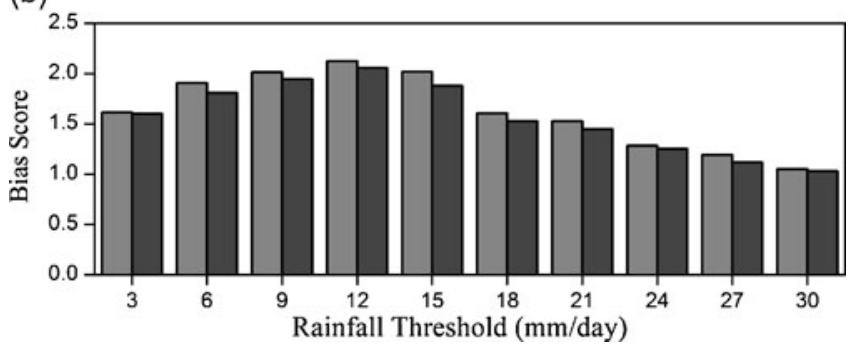

Figure 12. (a) Equitable threat score (ETS) and (b) bias in rainfall prediction with corresponding IMD gridded observations for different rainfall thresholds.

in the ETS has been seen with the assimilation of AWS data as compared to the CNT. Compared with TRMM, both (CNT and EXP) overestimate (figure 11b; bias score is more than 1) the rainfall. The bias remains same in both the runs, and is not improved much with the assimilation of AWS data. Figure 12 shows the ETS and BS computed using IMD data as the observed rainfall for different thresholds for the CNT and EXP runs. The model with the AWS data assimilation shows better skill in predicted rainfall over all the thresholds than without AWS data assimilation. This confirms the positive impact of the AWS data on the simulation of Indian summer monsoon rainfall. Performance of WRF model for the short range prediction of Indian summer monsoon rainfall has been examined by Das et al (2008) and Rakesh et al (2009a, 2009b). Rakesh et al (2009a, 2009b) have also reported similar kinds of ETS.

\section{Summary}

Weather Research and Forecasting (WRF-ARW) model and its 3D-Var assimilation system are used to assess the impact of the assimilation of AWS surface observations on model forecasts over the Indian region during the 2008 summer monsoon. The CNT and EXP forecasts are made for 24-hour each day starting at 0000 UTC from 1-30 July 2008 where the control run served as a baseline for verifying the assimilation experiments.

With the assimilation of AWS data, improvements are observed in analyzed lower level temperature and relative humidity, whereas minor improvements are found in wind speed. Assimi- lation of AWS data positively influenced on 2-m temperature and $\mathrm{RH}$ forecasts over northern and southern parts of India and largest improvement is seen in northern India and the Bay of Bengal. The rainfall prediction was also improved (marginally), relative to the control simulation, by incorporation of AWS data. Assimilation of AWS data improved the 24 -h rainfall prediction over the west coast of India and eastern India. This impact is mainly due to the improvement in the lower level moisture fields. Thus, increasing numbers of AWS can be viewed as a positive step towards the high resolution numerical modelling for short range forecast.

\section{Acknowledgements}

Authors are thankful to the National Center for Atmospheric Research (NCAR) for the WRF model. The global analyzed and forecast data provided by National Centers for Environmental Prediction (NCEP) are acknowledged with sincere thanks. We are thankful to NASA for the valuable data from TRMM website http://disc2.nascom. nasa.gov/Giovanni/tovas. The AWS data obtained from MOSDAC is gratefully acknowledged. Authors are thankful to the National Climate Centre, India Meteorological Department, Pune for providing the daily gridded rainfall data. The authors thank the Director and the Deputy Director, RESA of Space Applications Centre (SAC), ISRO, Ahmedabad for their encouragement and help.

\section{References}

Adler R F, Bolun D T, Curtis S and Nelkin E J 2000 Tropical rainfall distributions determined using TRMM combined with other satellite and rain gauge information; J. Appl. Meteor. 39 2007-2023.

Alapaty K, Seaman N L, Niyogi D S and Hanna A F 2001 Assimilating surface data to improve the accuracy of atmospheric boundary layer simulations; J. Appl. Meteor. $402068-2082$.

Barker D M, Huang W, Guo Y R, Bourgeois A J and Xiao Q N 2004 A three dimensional variational data assimilation system for MM5: Implementation and initial results; Mon. Weather Rev. 132 897-914.

Colle B A, Westrick K J and Mass C F 1999 Evaluation of MM5 and Eta 10 precipitation forecast over the Pacific Northwest during the cool season; Weather Forecast. 14 $137-154$.

Das S, Ashrit R, Mohandas S, Iyengar G R, Gupta M D, George J P, Rajagopal E N and Dutta S K 2008 Skills of different mesoscale models over Indian region during monsoon season: Forecast errors; J. Earth Syst. Sci. 117 603-620.

Dudhia J 1989 Numerical study of convection observed during the winter monsoon experiment using a mesoscale two-dimensional model; J. Atmos. Sci. 46 3077-3107. 
Ehrendorfer M 1992 Four-dimensional data assimilation: Comparison of variational and sequential algorithms; Quart. J. Roy. Meteorol. Soc. 118 673-713.

Guo Y R, Shin D H, Lee J, Xiao Q, Barker D and Kuo Y H 2002 Application of the MM5 3D-Var system for a heavy rain case over the Korean peninsula; Preprint of the twelfth PSU/NCAR mesoscale model user's workshop, 24-25 June 2002, Boulder, CO, pp. 161-165.

Haddad Z S, Smith E A, Kummerow C D, Iguchi T, Farrar M R, Durden S L, Alves M and Olson W S 1997 The TRMM day-1 radar/radiometer combined rain-profiling algorithm; J. Meteor. Soc. Japan 75 799-809.

Hong S Y and Dudhia J 2003 Testing of a new nonlocal boundary layer vertical diffusion scheme in Numerical weather prediction applications; 20th Conference on Weather Analysis and Forecasting/16th Conference on Numerical Weather Prediction, Seattle, WA.

Hong S Y and Pan H L 1996 Nonlocal boundary layer vertical diffusion in a medium range forecast model; Mon. Weather Rev. 124 2322-2339.

Kain J S 2004 The Kain-Fritsch convective parameterization: An update; J. Appl. Meteor. 43 170-181.

Lin Y L, Farley R D and Orville H D 1983 Bulk parameterization of the snow field in a cloud model; J. Climate Appl. Meteor. 22 1065-1092.

Mlawer E J, Taubman S J, Brown P D, Iacono M J and Clough S A 1997 Radiative transfer for inhomogeneous atmosphere: RRTM, a validated correlated-k model for the longwave; J. Geophys. Res. 102(D14) 16,663-16,682.

Parrish D F and Derber J C 1992 The National Meteorological Center's spectral statistical interpolation analysis system; Mon. Weather Rev. 120 1747-1763.

Rajeevan M, Bhate J, Kale J D and Lal B 2006 High resolution daily gridded rainfall data for the Indian region:
Analysis of break and active monsoon spells; Curr. Sci. $91296-306$.

Rakesh V, Singh R, Pal P K and Joshi P C 2009a Impacts of satellite-observed winds and total precipitable water on WRF short-range forecasts over the Indian region during the 2006 summer monsoon; Weather Forecast. 24 17061731.

Rakesh V, Singh R, Yuliya D, Pal P K and Joshi P C 2009b Impact of variational assimilation of MODIS thermodynamic profiles in the simulation of western disturbance; Int. J. Remote Sens. 30 4867-4889.

Ruggiero F H, Sashegyi K D, Madala R V and Raman S 1996 The use of surface observations in four-dimensional data assimilation using a mesoscale model; Mon. Weather Rev. 124 1018-1033.

Skamarock W C, Klemp J B, Dudhia J, Gill D O, Barker D M, Duda M G, Huang X Y, Wang W and Powers J G 2008 A description of the Advanced Research WRF Version 3. NCAR/TN-475 STR; NCAR Technical Note, Mesoscale and Microscale Meteorology Division, National Center of Atmospheric Research, June 2008, 113 pp.

Wang X, Barker D M, Snyder C and Hamill T M 2008 A hybrid ETKF-3DVAR data assimilation scheme for the WRF model. Part II: Real observation experiments; Mon. Weather Rev. 136 5132-5147.

Wu W S, Purser R J and Parrish D F 2002 Threedimensional variational analysis with spatially inhomogeneous covariances; Mon. Weather Rev. 130 29052916.

Yee S Y K and Jackson A J 1988 Blending of surface and rawinsonde data in mesoscale objective analysis; AFGL Tech. Rep. 88-0144, Air Force Geophysics Laboratory, Hanscom AFB, Massachusetts, 31 pp. [NTIS ADA203984]. 